THE DISTRIBUTION OF LEPTYSMA MARGINICOLLIS (SERV.).

BY SAMUEL H. SCUDDER, CAMBRIDGE, MASS.

A single mature and one or two immature specimens of a Leptysma taken July i 3 by Mr. A. P. Morse at Palm Springs in Southern California (on bunch grass in Palm Cañon), and a single specimen from the Colorado Desert, Aug. I3, sent me by the Stanford University, had the pale lateral stripe so faint and were found so far west of the regions from which our only known species, L. marginicollis (Serv.), had been reported, that I at first thought I had an undescribed species before me. Comparison, however, showed that there was no other mark of distinction and this mark was absent from several other specimens I found in my collection, collected by Crotch about San Diego, Cal., that is, in the same or adjoining counties. This greatly extends the published distribution of the species. In my recent Catalogue I gave this as the "Southern States east of Mississippi." If I had gone over my collection carefully, I should have found specimens from the above localities and also from northeast Fla., Feb. (Maynard), Ft. Reed, Fla., April (Comstock) Appalachicola, Fla. (Thaxter), Georgia (Morrison), North Carolina (Shute), Smithville, N. C., Nov. 22 (Maynard), Vigo Co., Ind. (Blatchley), Auburn, Ala. (Baker), Houston, Tex., on water plants Belfrage), Dallas, Tex., March 6 (Boll), Kansas (Uhler), and Nebraska (Miss Walker). Bruner does not give it in his list of Nebraska insects. It has also been reported from South Carolina (Stål) and Tennessee (De Haan), and I have received it from Biscayne Bay Fla. (Slosson). The range should therefore have been stated as Southern States from Atlantic to Pacific.

\title{
MISCELLANEOUS NOTES ON COCCIDAE FROM WESTERN MASSACHUSETTS.
}

BY GEO. B. KING, LAWRENCE, MASS.

All of the Coccids cited below were collected in the vicinity of Springfield, Mass. (Hampden County), by Dr. George Dimmock, who sent them to me for study, and the following records add considerably to our already large list, and many new food plants are here listed for the first time.

(I) Lecanium quercitronis Fitch. Several lots of this have been received, 

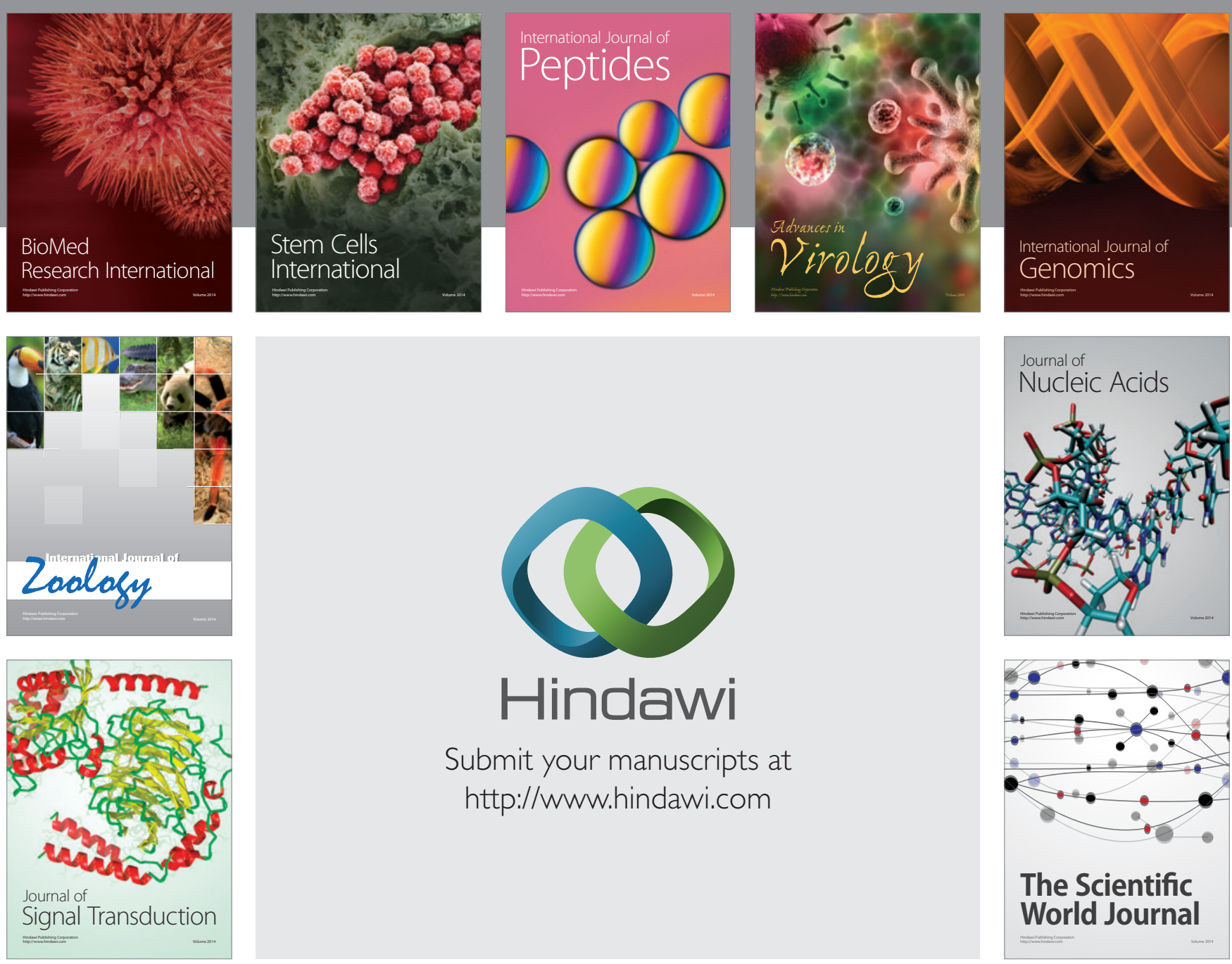

Submit your manuscripts at

http://www.hindawi.com
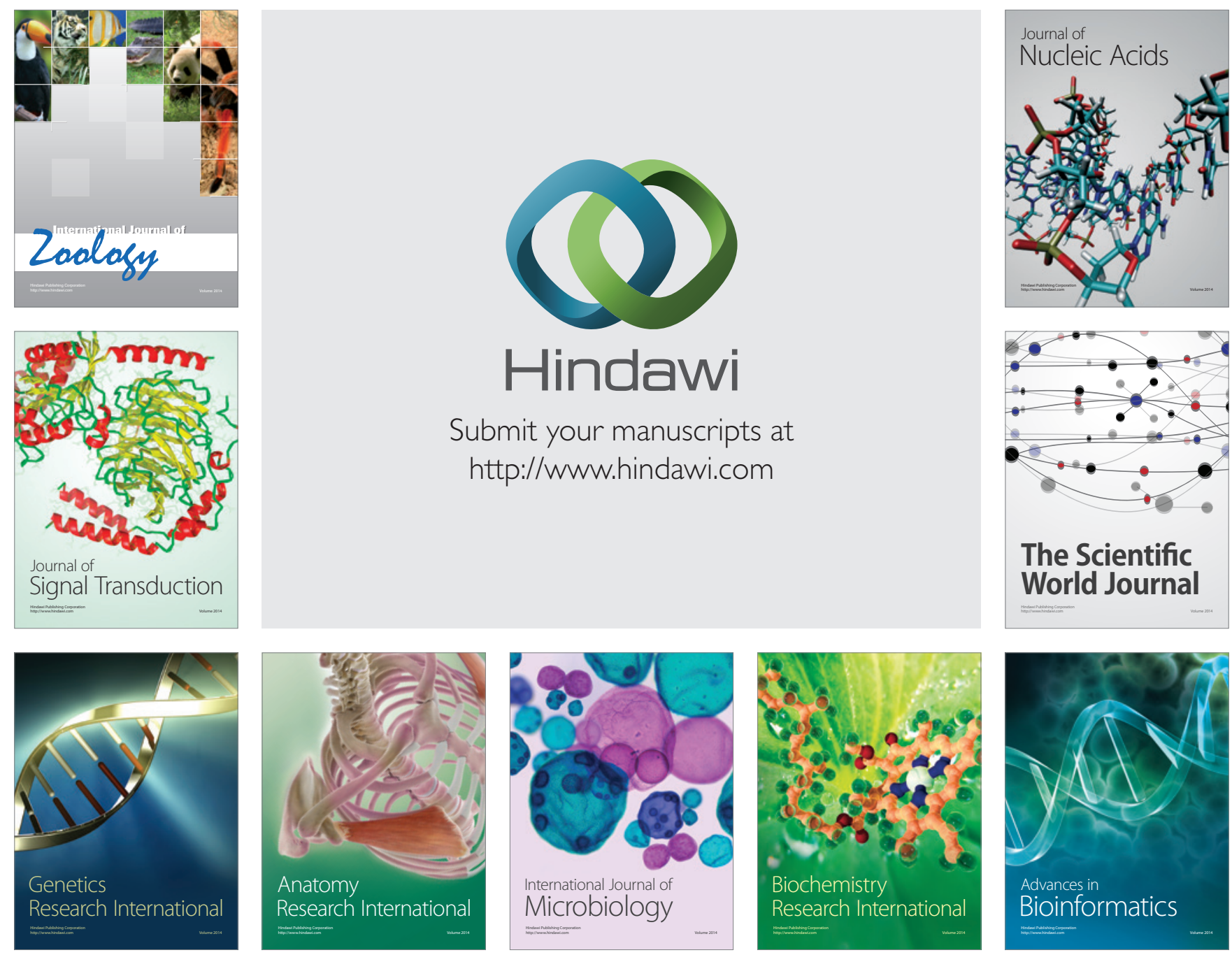

The Scientific World Journal
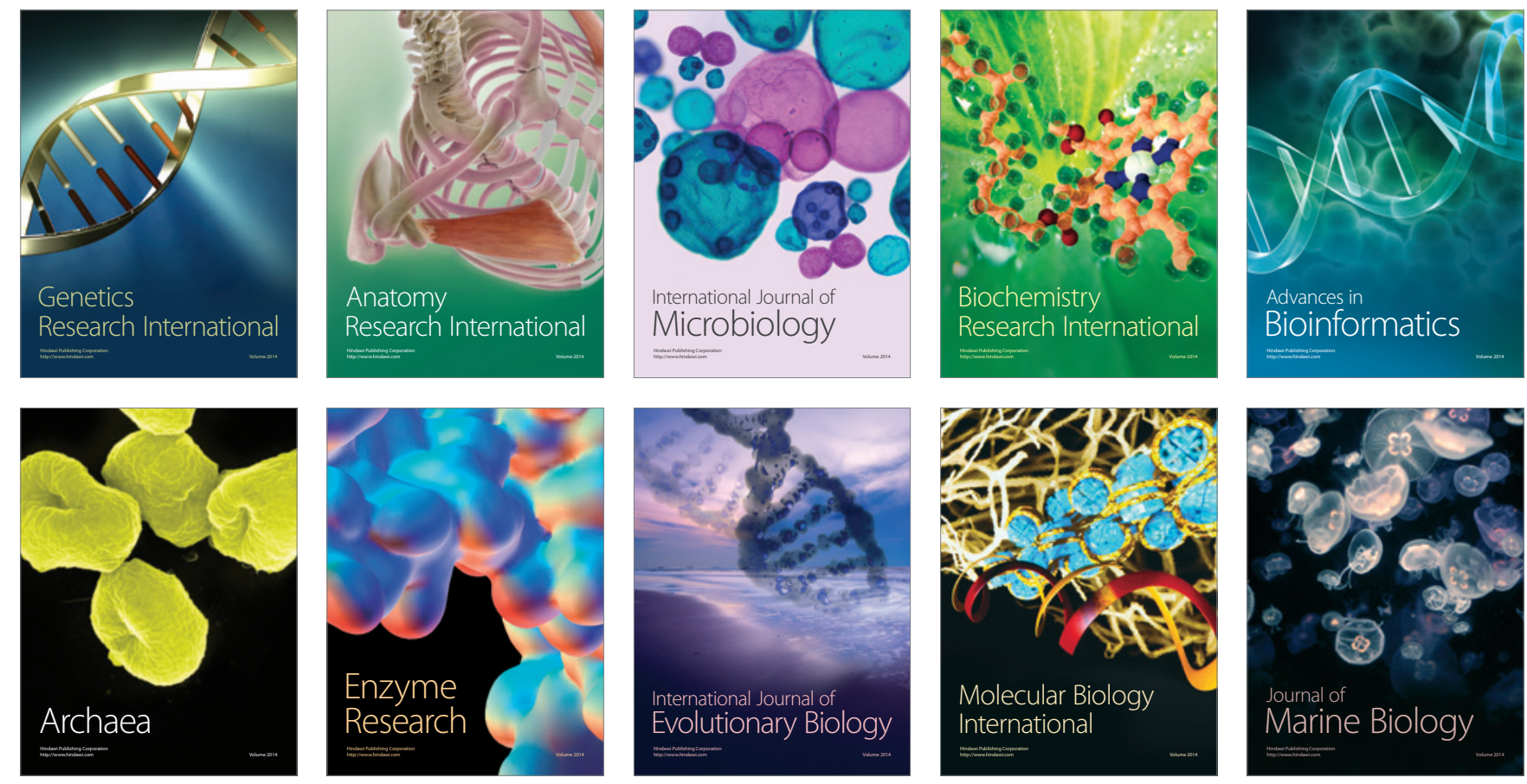